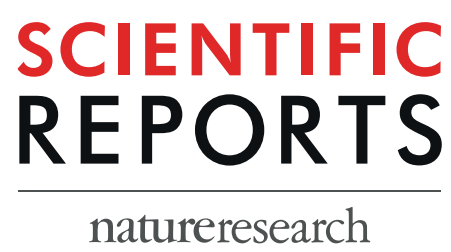

\title{
OPEN Killer cell immunoglobulin- like receptors (KIR) and human leukocyte antigen-C (HLA-C) allorecognition patterns in women with endometriosis
}

\author{
Ya-Ching Chou ${ }^{1,2,3,4}$, Chi-Huang Chen ${ }^{1,2}$, Ming-Jer Chen ${ }^{5,6}$, Ching-Wen Chang ${ }^{1}$, Pi-Hua Chen ${ }^{7,8}$, \\ Mu-Hsien Yu ${ }^{9}$, Yi-Jen Chen ${ }^{10,11}$, Eing-Mei Tsai ${ }^{12,13}$, Peng-Sheng Yang ${ }^{1}$, Shyr-Yeu Lin ${ }^{1,2}$ \& \\ Chii-Ruey Tzeng ${ }^{1,2^{*}}$
}

Endometriosis shares similarities with several autoimmune diseases. The human leukocyte antigen (HLA)-C genotype is associated with several human autoimmune diseases. HLA-C is a ligand of killer cell immunoglobulin receptors (KIRs) and is an essential regulator of natural killer cell activity, which is associated with endometriosis progression. Polymorphisms in HLA-C and KIR affect the activity of NK cells and susceptibility to several diseases. Therefore, we attempted to investigate an association between HLA-C genotype and KIR polymorphism and the occurrence of endometriosis. We tested the association of certain KIR and HLA-C combinations and the development of endometriosis by characterizing both KIR and HLA-C genes in 147 women with endometriosis and 117 controls. The HLA-C genotypes and KIR polymorphisms were analyzed via DNA-based method for higher-resolution genotyping. We found that the occurrence of $H L A-C * 03: 03 * 01$ was increased in endometriosis than in control groups. Analysis of various KIR haplotypes revealed differences between the endometriosis and control cohorts. The number of KIR centromeric A/A haplotypes was increased in the endometriosis group than controls. Moreover, the endometriosis cohort was characterized by reduced number of KIR2DS2-positive individuals in the Han Chinese population. Our current findings suggest that the KIR and $H L A-C$ genotypes are associated with the pathogenesis of endometriosis.

Endometriosis is a chronic gynecological disease with unknown etiology and is characterized by extra-uterine growth of endometrial tissue ${ }^{1}$. Endometriosis affects $6 \%$ to $10 \%$ of fertile women at the reproductive age and causes severe pelvic pain and infertility ${ }^{2-4}$. Familial and twin studies have reported that genetic factors are associated with the pathogenesis of endometriosis ${ }^{5-9}$. Cell-mediated and humoral immune responses are essential in the pathogenesis of endometriosis, since it is associated with various immunological abnormalities, particularly

\footnotetext{
${ }^{1}$ Center for Reproductive Medicine \& Sciences, Department of Obstetrics and Gynecology, Taipei Medical University Hospital, Taipei, Taiwan. ${ }^{2}$ Department of Obstetrics and Gynecology, School of Medicine, College of Medicine, Taipei Medical University, Taipei, Taiwan. ${ }^{3}$ Department of Biological Science and Technology, College of Biological Science and Technology, National Chiao Tung University, Hsinchu, Taiwan. ${ }^{4}$ Center for Intelligent Drug Systems and Smart Bio-devices (IDS ${ }^{2}$ B), National Chiao Tung University, Hsinchu, Taiwan. ${ }^{5}$ Department of Obstetrics and Gynecology and Women's Health, Taichung Veterans General Hospital, Taichung, Taiwan. ${ }^{6}$ School of Medicine, National Yang-Ming University, Taipei, Taiwan. ${ }^{7}$ Graduate Institute of Clinical Medicine, College of Medicine, Taipei Medical University, Taipei, Taiwan. ${ }^{8}$ Department of Obstetrics and Gynecology, Shuang Ho Hospital, Taipei Medical University, Taipei, Taiwan. ${ }^{9}$ Department of Obstetrics \& Gynecology, Tri-Service General Hospital, National Defense Medical Center, Taipei, Taiwan. ${ }^{10}$ Department of Obstetrics and Gynecology, Taipei Veterans General Hospital, Taipei, Taiwan. ${ }^{11}$ School of Medicine, Institute of Clinical Medicine, National Yang-Ming University, Taipei, Taiwan. ${ }^{12}$ General Research Centers of R\&D office, Kaohsiung Medical University, Kaohsiung, Taiwan. ${ }^{13}$ Division of Reproductive Medicine, Department of Obstetrics and Gynecology, Kaohsiung Medical University Hospital, Kaohsiung, Taiwan. *email: tzengcr@tmu.edu.tw
} 


\begin{tabular}{|l|l|l|l|}
\hline Characteristics & $\begin{array}{l}\text { Control } \\
\mathbf{n}=\mathbf{1 1 7}(\%)\end{array}$ & $\begin{array}{l}\text { Endometriosis } \\
\mathbf{n}=\mathbf{1 4 7}(\%)\end{array}$ & p value \\
\hline Age $^{\mathrm{a}}$ & $38.44(7.47)$ & $36.08(6.55)$ & 0.012 \\
\hline $\mathrm{BMI}^{\mathrm{a}}, \mathrm{kg} / \mathrm{m}^{2}$ & $23.01(4.47)$ & $21.58(3.47)$ & 0.0032 \\
\hline Age of menarche $^{\mathrm{a}}$ & $12.53(1.21)$ & $12.80(1.52)$ & 0.5968 \\
\hline Duration of Menstrual cycle $^{\mathrm{a}}$ & $27.95(4.95)$ & $28.45(2.97)$ & 0.1392 \\
\hline Dysmenorrhea $^{\mathrm{b}}, \mathrm{n}(\%)$ & $73(62.39)$ & $112(76.19)$ & 0.015 \\
\hline
\end{tabular}

Table 1. Patient demographic results. Abbreviations: BMI, body mass index; SD, standard deviation Mean (SD) for continuous variables. $\mathrm{n}(\%)$ for discontinuous variables. ${ }^{\mathrm{a}}$ Mann-Whitney test. ${ }^{\mathrm{b}} \chi^{2}$ test.

cell-mediated immunity ${ }^{10-12}$. The activities of cytotoxic T-cells and natural killer (NK) cells are dysregulated in women with endometriosis ${ }^{13-16}$. Increased serum levels of immunoglobulins and autoantibodies, decreased endometrial cell apoptosis, and the production of pro-inflammatory cytokines are observed in endometriosis patients, indicating that endometriosis shares many similarities with autoimmune disease ${ }^{11,12,17,18}$.

Major histocompatibility complex (MHC) genes, also known as human leukocyte antigen (HLA) genes, are located in chromosome 6p. The genes encoding the human MHC class I (HLA-A,HLA-B, and HLA-C) and class II (HLA-DR, HLA-DQ, and $H L A-D P)$ molecules are the most polymorphic loci in the human genome. HLA genes are polymorphic in binding and function in presenting antigen peptides to T-cells. HLA molecules are key factors involved in regulating the specificity of T-cell-mediated immune response in autoimmune and infectious diseases $^{19-21}$.

HLA Class I genes encode cell-surface proteins, whose primary functions are to present antigens to cytotoxic $\mathrm{CD}^{+} \mathrm{T}$-cells during the early immune responses ${ }^{19-21}$. Among these, HLA-C plays a minor role in regulating antigen-specific T-cell responses because of low cell surface expression ${ }^{22}$. HLA-C acts as a ligand for killer cell immunoglobulin-like receptors (KIRs), which regulate natural killer (NK) cell-mediated cytotoxicity. The human immunodeficiency virus Nef protein selectively downregulates the production of HLA-A and HLA-B molecules to suppress cytotoxic CD8 ${ }^{+}$T lymphocyte responses ${ }^{23}$. However, Nef maintains stable HLA-C expression levels to inhibit NK cell activation and renders HLA-C as a T-cell restriction element during HIV infection ${ }^{24}$. Importantly, the HLA-C genotype has been implicated in several autoimmune diseases, including Graves' disease, psoriasis, and Crohn's disease $\mathrm{e}^{20,22,23,25,26}$.

NK cells are lymphocytes that serve as vital components of the immune system by regulating early responses against infected or transformed cells via cytokine production and direct cytotoxicity ${ }^{27}$. KIRs are a family of membrane glycoproteins expressed by NK cells. KIRs contain two or three extracellular immunoglobulin-like domain molecules (D) with a long (L) or short (S) cytoplasmic tail ${ }^{28}$. The KIR gene is located on chromosome $19 \mathrm{q} 13.4$ on the leukocyte receptor complex. KIR exhibits activating and inhibitory effects with extensive haplotypic and allelic polymorphisms ${ }^{29-31}$. The 16 KIR genes comprise the following: six genes encoding activating KIR (2DS1-5 and 3DS1), seven genes encoding inhibitory KIR (2DL1-3, 5 and 3DL1-2), KIR2DL4, which can exert both inhibitory and activating activity, and two pseudogenes (2DP1 and 3DP1). Furthermore, KIR3DL3, KIR3DP1, KIR2DL4, and KIR3DL2 are framework genes and are always present in the genome ${ }^{32}$.

The primary ligands of KIR are HLA-C molecules, which are divided into two groups, namely $\mathrm{C} 1$ and $\mathrm{C} 2$, based on the amino acid at position 80 [HLA-C C1 groups (HLA-C1), asparagine (N) at position 80: $\mathrm{C}^{*} 01,03,07$ (01-06), 08, $12(02,03,06), 13,14,15: 07,16(01,03,04)$; HLA-C C2 groups (HLA-C2), lysine (K) at position 80: $\left.\mathrm{C}^{*} 02,04,05,06,07(07), 12(04,05,42), 15,16(02), 17,18\right]^{32,33}$. The inhibitory receptors KIR2DL2 and KIR2DL3 and activating receptor KIR2DS2 share the same ligand HLA-C1. Activating KIR2DS2 has been reported to be in strong linkage disequilibrium and highly homologous to KIR2DL2. KIR2DL1 and KIR2DS1 bind to HLA-C2 ${ }^{3134-36}$. Combinations of HLA-C with KIR2DS1 and KIR2DS2 have been reported to correlate with the occurrence of autoimmune diseases, leukemia, and inflammatory diseases ${ }^{37-42}$. Polymorphisms in the genes encoding HLA-C and KIR affect NK cells activity and susceptibility to several diseases ${ }^{31}$. HLA genotyping is traditionally performed using a serological method. However, detection of the HLA-C genotype via serological typing is difficult because of the low HLA-C expression levels at the cell surface, the lack of suitable antisera, and difficulties in protein isolation ${ }^{22}$. Therefore, we employed a DNA-based method for higher-resolution genotyping and investigated the association between the $H L A-C$ genotype and endometriosis. Moreover, to analyze the association between certain KIR-HLA-C combinations and the development of endometriosis, we characterized both KIR and HLA-C gene polymorphisms in 147 women with endometriosis and 117 controls.

\section{Results}

Frequency distributions of HLA-C alleles among endometriosis and control groups. The demographic results of endometriosis and control groups are shown in Table 1. HLA-C allele frequencies in endometriosis patients $(\mathrm{n}=147,294$ alleles $)$ and control patients $(\mathrm{n}=117,234$ alleles $)$ were determined using a sequence-based typing method. The presence of HLA-C*03:03:01 significantly increased the risk of endometriosis with $\mathrm{p}=0.0473$ [Odds Ratio $(\mathrm{OR})=2.811,95 \%$ confidence interval $(\mathrm{CI})=1.021-7.738$ ] and the statistical power was $43.8 \%$ (Table 2). After multiple test analyses using Bonferroni correction, the association was not significant.

Frequency distributions of $H L A-C$ group among endometriosis and control groups. We evaluated whether the HLA-C group C1 (HLA-C1) and HLA-C group C2 (HLA-C2) were associated with 


\begin{tabular}{|c|c|c|c|c|c|c|c|}
\hline \multirow[b]{2}{*}{ HLA-C } & \multicolumn{2}{|c|}{$\begin{array}{l}\text { Control }(n=117, \\
234 \text { alleles })\end{array}$} & \multicolumn{2}{|c|}{$\begin{array}{l}\text { Endometriosis ( } \mathrm{n}=147 \text {, } \\
294 \text { alleles) }\end{array}$} & \multirow[b]{2}{*}{ OR } & \multirow[b]{2}{*}{$95 \% \mathrm{CI}$} & \multirow[b]{2}{*}{ P value } \\
\hline & $\mathrm{n}$ & $\%$ & $\mathbf{n}$ & $\%$ & & & \\
\hline C*01:02:01 & 56 & 23.9 & 59 & 20.1 & 0.798 & 0.5273 to 1.208 & 0.2907 \\
\hline$C^{*} 01: 08$ & 0 & 0.0 & 1 & 0.3 & 2.397 & 0.09712 to 59.16 & 1 \\
\hline$C * 02: 02: 02: 01$ & 0 & 0.0 & 2 & 0.7 & 4.009 & 0.1914 to 83.97 & 0.5055 \\
\hline$C^{*} 03: 02: 01$ & 24 & 10.3 & 33 & 11.2 & 1.106 & 0.6342 to 1.930 & 0.7786 \\
\hline$C^{*} 03: 03: 01$ & 5 & 2.1 & 17 & 5.8 & 2.811 & 1.021 to 7.738 & $0.0473^{*}$ \\
\hline$C * 03: 04: 01: 01$ & 30 & 12.8 & 34 & 11.6 & 0.8892 & \begin{tabular}{|l|}
0.5265 to 1.502 \\
\end{tabular} & 0.6886 \\
\hline C*03:04:04 & 0 & 0.0 & 4 & 1.4 & 7.265 & 0.3889 to 135.7 & 0.1333 \\
\hline C*04:01:01:01 & 10 & 4.3 & 12 & 4.1 & 0.9532 & 0.4043 to 2.247 & 1 \\
\hline $\begin{array}{l}{ }^{*} 04: 03 \\
\end{array}$ & 4 & 1.7 & 4 & 1.4 & 0.7931 & 0.1962 to 3.207 & 0.7375 \\
\hline$C * 06: 02: 01: 01$ & 7 & 3.0 & 5 & 1.7 & 0.561 & 0.1757 to 1.792 & 0.3849 \\
\hline$C * 07: 01: 01: 01$ & 1 & 0.4 & 0 & 0.0 & 0.2643 & 0.01071 to 6.523 & 0.4432 \\
\hline$C * 07: 02: 01: 01$ & 39 & 16.7 & 61 & 20.7 & 1.309 & 0.8391 to 2.042 & 0.264 \\
\hline C*07:04:01 & 1 & 0.4 & 1 & 0.3 & 0.7952 & 0.04944 to 12.79 & 1 \\
\hline C*07:359 & 1 & 0.4 & 0 & 0.0 & 0.2643 & 0.01071 to 6.523 & 0.4432 \\
\hline C*08:01:01 & 21 & 9.0 & 20 & 6.8 & 0.7404 & 0.3911 to 1.401 & 0.4138 \\
\hline C*08:03:01 & 0 & 0.0 & 1 & 0.3 & 2.397 & 0.09712 to 59.16 & 1 \\
\hline$C * 12: 02: 02$ & 15 & 6.4 & 14 & 4.8 & \begin{tabular}{|l|l|}
0.73 \\
\end{tabular} & 0.3449 to 1.545 & 0.4456 \\
\hline$C^{*} 12: 03: 01: 01$ & 3 & 1.3 & 1 & 0.3 & 0.2628 & 0.02714 to 2.544 & 0.3269 \\
\hline C*14:02:01 & 6 & 2.6 & 9 & 3.1 & 1.2 & 0.4208 to 3.422 & 0.7975 \\
\hline C*14:02:03 & 0 & 0.0 & 1 & 0.3 & 2.397 & 0.09712 to 59.16 & 1 \\
\hline C*15:02:01 & 8 & 3.4 & 14 & 4.8 & 1.413 & 0.5822 to 3.427 & 0.5151 \\
\hline C*15:05:01 & 1 & 0.4 & 0 & 0.0 & 0.2643 & 0.01071 to 6.523 & 0.4432 \\
\hline C*16:02:01 & 1 & 0.4 & 0 & 0.0 & 0.2643 & 0.01071 to 6.523 & 0.4432 \\
\hline$C^{*} 16: 04: 01$ & 1 & 0.4 & 1 & 0.3 & 0.7952 & 0.04944 to 12.79 & 1 \\
\hline
\end{tabular}

Table 2. Distribution of the $H L A-C$ alleles in the endometriosis and control groups. Each HLA allele has four unique sets denoted by different numbers that are separated by a colon. The first two digits often correspond to the serological antigen; the two digits after the first colon denote the subtypes and order in the genome from the IMGT/HLA Database (www.ebi.ac.uk/imgt/hla/). The differences in HLA-C allele frequencies between the endometriosis and control groups were analyzed using the Fisher's exact test. Significance was set at a $\mathrm{P}$ value $<0.05$ and the statistical power was $43.8 \%$ calculated by $\mathrm{G}^{*}$ Power. OR indicates odds ratio. CI indicates confidence interval.

\begin{tabular}{|l|l|l|l|l|l|l|l|}
\hline \multirow{2}{*}{ HLA-C } & \multicolumn{2}{|l|}{$\begin{array}{l}\text { Control } \\
(\mathbf{n = 1 1 7 )}\end{array}$} & \multicolumn{2}{l|}{$\begin{array}{l}\text { Endometriosis } \\
(\mathbf{n = 1 4 7})\end{array}$} & & & \\
\cline { 2 - 5 } & $\mathbf{n}$ & $\%$ & $\mathbf{n}$ & $\mathbf{\%}$ & OR & 95\% CI & p value \\
\hline C1 & 115 & 98.3 & 146 & 99.3 & 2.539 & 0.2273 to 28.37 & 0.5859 \\
\hline C2 & 29 & 24.8 & 36 & 24.5 & 0.9842 & 0.5602 to 1.729 & 1 \\
\hline C1C1 & 88 & 75.2 & 111 & 75.5 & 1.016 & 0.5783 to 1.785 & 1 \\
\hline C2C2 & 2 & 1.7 & 1 & 0.7 & 0.3938 & 0.03525 to 4.400 & 0.5859 \\
\hline C1C2 & 27 & 23.1 & 35 & 23.8 & 1.042 & 0.5869 to 1.849 & 1 \\
\hline
\end{tabular}

Table 3. Distribution of HLA-C ligand in endometriosis and control groups. Two-sided Fisher's exact test was used to estimate the differences between endometriosis and control groups. n: number of cases with relevant genotypes, OR: odds ratio, CI: confidence interval, Significance was set at a $\mathrm{P}$ value $<0.05$.

endometriosis. Analysis revealed no significant differences in HLA-C1 and HLA-C2 frequencies in the endometriosis and control groups (Table 3).

Frequency distributions of $K I R$ genotypes among endometriosis and control groups. Using sequence-specific PCR amplification, we analyzed the KIR genotypes in the endometriosis and control groups. The frequencies of the KIR genotypes in women with endometriosis and controls and their statistical associations are presented in Table 4 . The presence of KIR2DS2 significantly reduced the risk of endometriosis with $\mathrm{p}=0.0394$ $[(\mathrm{OR})=0.5577,95 \% \mathrm{CI}=0.3251-0.9569]$ and the statistical power was $68.6 \%$. After multiple test analyses using Bonferroni correction, the association was not significant. The two groups showed no significant differences in the remaining KIR genotypes. 


\begin{tabular}{|c|c|c|c|c|c|c|c|}
\hline \multirow[b]{2}{*}{ Inhibitory KIR } & \multicolumn{2}{|c|}{ Control $(n=117)$} & \multicolumn{2}{|c|}{$\begin{array}{l}\text { Endometriosis } \\
(\mathrm{n}=147)\end{array}$} & \multirow[b]{2}{*}{ OR } & \multirow[b]{2}{*}{ 95\% CI } & \multirow[b]{2}{*}{ p value } \\
\hline & \begin{tabular}{|l|}
$n$ \\
\end{tabular} & $\%$ & $n$ & $\%$ & & & \\
\hline KIR2DL1 & 114 & 97.4 & 147 & 100.0 & 9.017 & 0.4608 to 176.5 & 0.0858 \\
\hline KIR2DL2 & 37 & 31.6 & 31 & 21.1 & 0.5778 & 0.3314 to 1.007 & 0.0653 \\
\hline KIR2DL3 & 114 & 97.4 & 146 & 99.3 & 3.842 & 0.3942 to 37.45 & 0.3252 \\
\hline KIR2DL4 & 117 & 100.0 & 147 & 100.0 & - & - & - \\
\hline KIR2DL5 & 52 & 44.4 & 49 & 33.3 & 0.625 & 0.3788 to 1.031 & 0.0747 \\
\hline KIR3DL1 & 115 & 98.3 & 145 & 98.6 & 1.261 & 0.1748 to 9.093 & 1 \\
\hline KIR3DL2 & 117 & 100.0 & 147 & 100.0 & - & - & - \\
\hline KIR3DL3 & 117 & 100.0 & 147 & 100.0 & - & - & - \\
\hline \multicolumn{8}{|l|}{ Activating KIR } \\
\hline KIR2DS1 & 39 & 33.3 & 46 & 31.3 & 0.9109 & 0.5421 to 1.531 & 0.7911 \\
\hline KIR2DS2 & 41 & 35.0 & 34 & 23.1 & 0.5577 & 0.3251 to 0.9569 & 0.0394* \\
\hline KIR2DS3 & 29 & 24.8 & 25 & 17.0 & 0.6218 & 0.3409 to 1.134 & 0.1273 \\
\hline KIR2DS4 $^{*}$ & 113 & 96.6 & 143 & 97.3 & 1.265 & 0.3096 to 5.173 & 0.7358 \\
\hline KIR2DS4f & 89 & 76.1 & 117 & 79.6 & 1.227 & 0.6840 to 2.201 & 0.5503 \\
\hline KIR2DS4d & 60 & 51.3 & 76 & 51.7 & 1.017 & 0.6255 to 1.653 & 1 \\
\hline KIR2DS5 & 24 & 20.5 & 25 & 17.0 & 0.7941 & 0.4264 to 1.479 & 0.5249 \\
\hline KIR3DS1 & 44 & 37.6 & 48 & 32.7 & 0.8044 & 0.4836 to 1.338 & 0.4365 \\
\hline \multicolumn{8}{|l|}{ Pseudogene } \\
\hline KIR2DP1 & 114 & 97.4 & 147 & 100.0 & 9.017 & 0.4608 to 176.5 & 0.0858 \\
\hline KIR3DP1 & 117 & 100.0 & 147 & 100.0 & - & - & - \\
\hline
\end{tabular}

Table 4. Genetic association between KIR gene in endometriosis and control groups. ${ }^{\text {TT }}$ The gene was considered positive if either of the two forms were present. KIR2DS4f - full-length KIR2DS4 allele variant. KIR2DS4d - deleted KIR2DS4 allele variant. Two-sided Fisher's exact test was used to estimate the differences between endometriosis and control groups. n: number of cases with relevant genotypes, OR: odds ratio, CI: confidence interval, *versus controls, $\mathrm{p}<0.05$ and the statistical power was $68.6 \%$ calculated by $\mathrm{G} *$ Power.

Frequency distributions of $K I R$ haplotypes among endometriosis and control groups. The frequencies of the KIR haplotypes in women with endometriosis and controls and their statistical associations are presented in Table 5. The $\chi^{2}$ value was calculated by Hardy-Weinberg analysis $\left(\chi^{2}>3.841\right.$ showed the subgroup was deviating from the Hardy-Weinberg equilibrium). We revealed differences between the endometriosis and control cohorts. The number of KIR centromeric A/A haplotypes was increased in the endometriosis group than controls with $\mathrm{p}=0.0394[(\mathrm{OR})=1.793,95 \% \mathrm{CI}=1.045-3.076]$ and the statistical power was $68.6 \%$.

Combinations of KIR and their HLA-C ligands. The frequencies of KIR and their HLA-C ligands were analyzed for their statistical associations with endometriosis (Table 6). HLA-C C1 groups are recognized by KIR2DL2/2DS2 and KIR2DL3, while HLA-C C2 groups are recognized by KIR2DL1/2DS1. Moreover, KIR2DL2/2DL3 also binds to some HLA-C C2 molecules, and KIR2DS4 binds to some HLA-C1 and HLA-C2 ${ }^{31,34-36}$. The molecular interactions of KIR gene-HLA-ligands were calculated from the KIR frequency of a total number of HLA ligands. The total number of HLA ligands is shown in Table 3. We calculated the KIR frequency in the combination of different HA ligands. Analysis of various KIR-HLA-C combinations revealed no significant differences between the endometriosis and control cohorts (Table 6). The frequency of KIR haplotypes and HLA-C combinations also showed no significant differences between the endometriosis and control groups (Table 7).

\section{Discussion}

Several factors are involved in the pathogenesis of endometriosis including genetic, neuroendocrine, and immunological factors ${ }^{43-45}$. Abnormal immune responses are recognized in endometriosis patients, including excessive inflammatory cytokine secretion, autoantibody production, and NK cell regulation ${ }^{17,18}$. Endometriosis shares similar characteristics with autoimmune diseases ${ }^{11,12,17,18}$. HLA-C affects viral infections and is implicated in several human autoimmune diseases ${ }^{22}$. HLA-C*06:02 is associated with severe early-onset psoriasis. HLA-C *12:02 was found to be associated with increased susceptibility to Crohn's disease ${ }^{20}$. HLA-C*03 restricts the cytotoxic $\mathrm{CD} 8^{+} \mathrm{T}$-cell responses during the Epstein-Barr virus and human immunodeficiency virus infections, as well as during co-infection with the influenza virus and the Sendai virus. Herein, we analyzed the associations between HLA-C alleles and endometriosis. Consequently, the presence of HLA-C*03:03:01 increased the risk of endometriosis in Asian women (Table 2). However, after multiple test analyses using Bonferroni correction, the association was not significant.

Previous studies reported no association between HLA genotypes and endometriosis in Caucasian women with endometriosis and controls, as assessed by serological typing ${ }^{46-48}$. A serological study showed increased frequencies of the $H L A-B * 54$ and $H L A-C * 07$ alleles in Japanese patients with endometriosis ${ }^{49}$. In a recent study, PCR-restriction fragment length polymorphism analysis revealed that the HLA-DRB1*14:03 and $H L A-D Q B 1 * 03: 01$ alleles are associated with endometriosis in Japanese women ${ }^{50,51}$. Another study reported an 


\begin{tabular}{|c|c|c|c|c|c|c|c|}
\hline \multirow[b]{2}{*}{ Centromeric } & \multicolumn{2}{|c|}{ Control $(n=117)$} & \multicolumn{2}{|c|}{$\begin{array}{l}\text { Endometriosis } \\
(\mathrm{n}=147)\end{array}$} & \multirow[b]{2}{*}{ OR } & \multirow[b]{2}{*}{$95 \%$ CI } & \multirow[b]{2}{*}{ p value } \\
\hline & $\mathbf{n}$ & $\%$ & $\mathbf{n}$ & $\%$ & & & \\
\hline Cen-A/A & 76 & 65.0 & 113 & 76.9 & 1.793 & 1.045 to 3.076 & 0.0394* \\
\hline Cen-A/B & 38 & 32.5 & 33 & 22.4 & 0.6018 & 0.3480 to 1.041 & 0.0713 \\
\hline Cen-B/B & 3 & 2.6 & 1 & 0.7 & 0.2603 & 0.02670 to 2.537 & 0.3252 \\
\hline$x^{2}$ & 0.47 & & 0.73 & & & & \\
\hline \multicolumn{8}{|l|}{ Telomeric } \\
\hline Tel-A/A & 71 & 60.7 & 96 & 65.3 & 1.22 & 0.7374 to 2.017 & 0.4442 \\
\hline Tel-A/B & 42 & 35.9 & 47 & 32.0 & 0.8393 & 0.5026 to 1.402 & 0.5151 \\
\hline Tel-B/B & 4 & 3.4 & 4 & 2.7 & 0.7902 & 0.1933 to 3.230 & 0.7358 \\
\hline$x^{2}$ & 0.55 & & 0.39 & & & & \\
\hline
\end{tabular}

Table 5. Frequency of centromeric and telomeric KIR haplotypes in endometriosis and control groups. Twosided Fisher's exact test was used to estimate the differences between endometriosis and control groups. $\mathrm{n}$ : number of cases with relevant genotypes, OR: odds ratio, CI: confidence interval, $\chi^{2}$ value was calculated by Hardy-Weinberg analysis $\left(\chi^{2}>3.841\right.$ showed the subgroup was deviating from the Hardy-Weinberg equilibrium). *versus controls, $\mathrm{P}<0.05$ and the statistical power was $68.6 \%$ calculated by $\mathrm{G} *$ Power.

\begin{tabular}{|c|c|c|c|c|c|c|c|}
\hline \multirow{2}{*}{$\begin{array}{l}\text { Inhibitory KIR-ligand } \\
\text { association }\end{array}$} & \multicolumn{2}{|c|}{ Control } & \multicolumn{2}{|c|}{ Endometriosis } & \multirow[b]{2}{*}{ OR } & \multirow[b]{2}{*}{ 95\% CI } & \multirow[b]{2}{*}{ p value } \\
\hline & $\mathbf{n}$ & $\%$ & $\mathbf{n}$ & $\%$ & & & \\
\hline KIR2DL1-HLA-C1/C2 & 27 & 100.0 & 35 & 100.0 & - & - & - \\
\hline KIR2DL1-HLA-C2/C2 & 1 & 50.0 & 1 & 100.0 & 3 & $\begin{array}{l}0.05947 \text { to } \\
151.3\end{array}$ & 1 \\
\hline KIR2DL2-HLA-C1/C1 & 25 & 28.4 & 20 & 18.0 & 0.5538 & 0.2834 to 1.083 & 0.0902 \\
\hline KIR2DL2-HLA-C1/C2 & 10 & 37.0 & 11 & 31.4 & 0.7792 & 0.2704 to 2.245 & 0.7876 \\
\hline KIR2DL3-HLA-C1/C1 & 86 & 97.7 & 110 & 99.1 & 2.558 & 0.2280 to 28.70 & 0.5847 \\
\hline KIR2DL3-HLA-C1/C2 & 26 & 96.3 & 35 & 100.0 & 4.019 & 0.1573 to 102.7 & 0.4355 \\
\hline \multicolumn{8}{|c|}{ Activating KIR-ligand association } \\
\hline KIR2DS1-HLA-C1/C2 & 5 & 18.5 & 13 & 37.1 & 2.6 & 0.7918 to 8.538 & 0.1593 \\
\hline KIR2DS1-HLA-C2/C2 & 2 & 100.0 & 0 & 0.0 & 0.0667 & $\begin{array}{l}0.0008081 \\
\text { to } 5.5\end{array}$ & 0.3333 \\
\hline KIR2DS2-HLA-C1/C1 & 28 & 31.8 & 23 & 20.7 & 0.5601 & 0.2947 to 1.064 & 0.1016 \\
\hline KIR2DS2-HLA-C1/C2 & 11 & 40.7 & 11 & 31.4 & 0.6667 & 0.2337 to 1.902 & 0.5932 \\
\hline
\end{tabular}

Table 6. Distribution of molecular interactions of KIR gene-HLA-ligands in endometriosis and control groups. The molecular interactions of KIR gene-HLA-ligands were shown in the frequency of the KIR gene of HLAligands, which was calculated from the KIR frequency of the total number of HLA ligands. The total number of HLA ligands is shown in Table 3. Two-sided Fisher's exact test was used to estimate the differences between endometriosis and control groups. n: number of cases with relevant genotypes, OR: odds ratio, CI: confidence interval.

association between the $H L A-A * 24, H L A-B * 07: 02, H L A-C * 07: 02$, and $H L A-D R B 1 * 01: 01$ haplotypes and endometriosis in Japanese women ${ }^{52}$. A previous study showed that $H L A-D R B 1$ alleles were not associated with endometriosis in Polish women ${ }^{53}$. A literature search identified similar reports from China, which showed an association between endometriosis and the $H L A-B * 46, H L A-D R B 1 * 15$, and $H L A-D Q A 1 * 0401$ alleles $^{54-56}$. The reasons underlying the discrepancies observed among these studies are unclear; however, the results may have been influenced by differences in the ethnicities of the women in the study cohorts and the differences in the detection methods.

The frequency of KIR3DS1 was significantly lower in endometriosis patients compared to control patients ${ }^{57}$. Moreover, the protective effect of the KIR2DS5 gene was observed in endometriosis patients ${ }^{58}$. Moreover, Nowak et al. showed that the protective effect of KIR2DS5 was present only in the women who harbored the HLA-C C2 group $^{59}$. Our current findings revealed that a lower proportion of endometriosis groups, which was characterized by the presence of activating KIR2DS2 compared to the control groups (Table 4). Previous studies have shown that KIR2DL2 is in the linkage disequilibrium with KIR2DS2, which caused the relative activation of KIR receptor, which is responsible for the loss of recognition of HLA-C $\mathrm{C}^{60-62}$. The different ethnic populations showed different values of KIR polymorphisms in elucidating genetic relationships among human populations ${ }^{63}$. Moreover, HLA genotyping is traditionally performed using a serological method. Therefore, these discrepancies can be influenced by ethnic or assay methods as they do for discrepancies among HLA alleles.

NK cell activity has been reported to be a crucial factor in the recognition and lysis of endometrial cells. NK cell activity and quantity were found to be controversial in women with endometriosis relative to controls ${ }^{15,64-68}$. The observed increase in the proportion of CD158a $\mathrm{a}^{+}$(KIR2DL1) NK cells in the peripheral blood and peritoneal fluid in endometriosis patients suggested reduced NK cell cytotoxicity in endometriosis ${ }^{69}$. Moreover, the decrease 


\begin{tabular}{|c|c|c|c|c|c|c|c|c|}
\hline \multirow[b]{2}{*}{ KIR haplotypes } & \multirow{2}{*}{$\begin{array}{l}\text { HLA-C } \\
\text { genotypes }\end{array}$} & \multicolumn{2}{|c|}{ Control } & \multicolumn{2}{|c|}{ Endometriosis } & \multirow[b]{2}{*}{ OR } & \multirow[b]{2}{*}{$95 \%$ CI } & \multirow[b]{2}{*}{ P value } \\
\hline & & $\mathbf{n}$ & $\%$ & $\mathbf{n}$ & $\%$ & & & \\
\hline Cen-A/A & $\mathrm{C} 1 / \mathrm{C} 1$ & 60 & 68.2 & 88 & 79.3 & 1.786 & 0.9397 to 3.393 & 0.1016 \\
\hline Cen-A/A & $\mathrm{C} 1 / \mathrm{C} 2$ & 16 & 59.3 & 24 & 68.6 & 1.5 & 0.5257 to 4.280 & 0.5932 \\
\hline Cen-A/A & $\mathrm{C} 2 / \mathrm{C} 2$ & 0 & 0.0 & 1 & 100.0 & 15 & 0.1818 to 1238 & 0.3333 \\
\hline Cen-A/B & $\mathrm{C} 1 / \mathrm{C} 1$ & 26 & 29.5 & 22 & 19.8 & 0.5895 & 0.3065 to 1.134 & 0.1338 \\
\hline Cen-A/B & $\mathrm{C} 1 / \mathrm{C} 2$ & 10 & 37.0 & 11 & 31.4 & 0.7792 & 0.2704 to 2.245 & 0.7876 \\
\hline Cen-A/B & $\mathrm{C} 2 / \mathrm{C} 2$ & 2 & 100.0 & 0 & 0.0 & 0.0667 & 0.0008081 to 5.5 & 0.3333 \\
\hline Cen-B/B & $\mathrm{C} 1 / \mathrm{C} 1$ & 2 & 2.3 & 1 & 0.9 & 0.3909 & 0.03484 to 4.385 & 0.5847 \\
\hline Cen-B/B & $\mathrm{C} 1 / \mathrm{C} 2$ & 1 & 3.7 & 0 & 0.0 & 0.2488 & 0.009738 to 6.358 & 0.4355 \\
\hline Cen-B/B & $\mathrm{C} 2 / \mathrm{C} 2$ & 0 & 0.0 & 0 & 0.0 & - & - & - \\
\hline Tel-A/A & $\mathrm{C} 1 / \mathrm{C} 1$ & 50 & 56.8 & 74 & 66.7 & 1.52 & 0.8529 to 2.709 & 0.1853 \\
\hline Tel-A/A & $\mathrm{C} 1 / \mathrm{C} 2$ & 21 & 77.8 & 21 & 60.0 & 0.4286 & 0.1382 to 1.329 & 0.1758 \\
\hline Tel-A/A & $\mathrm{C} 2 / \mathrm{C} 2$ & 0 & 0.0 & 1 & 100.0 & 15 & 0.1818 to 1238 & 0.3333 \\
\hline Tel-A/B & $\mathrm{C} 1 / \mathrm{C} 1$ & 35 & 39.8 & 33 & 29.7 & 0.6407 & 0.3551 to 1.156 & 0.1755 \\
\hline Tel-A/B & $\mathrm{C} 1 / \mathrm{C} 2$ & 6 & 22.2 & 14 & 40.0 & 2.333 & 0.7523 to 7.237 & 0.1758 \\
\hline Tel-A/B & $\mathrm{C} 2 / \mathrm{C} 2$ & 1 & 50.0 & 0 & 0.0 & 0.3333 & 0.0066 to 16.82 & 1 \\
\hline Tel-B/B & $\mathrm{C} 1 / \mathrm{C} 1$ & 3 & 3.4 & 4 & 3.6 & 1.059 & 0.2307 to 4.863 & 1 \\
\hline Tel-B/B & $\mathrm{C} 1 / \mathrm{C} 2$ & 0 & 0.0 & 0 & 0.0 & - & - & - \\
\hline Tel-B/B & $\mathrm{C} 2 / \mathrm{C} 2$ & 1 & 50.0 & 0 & 0.0 & 0.3333 & 0.0066 to 16.82 & 1 \\
\hline
\end{tabular}

Table 7. Distribution of molecular interactions of KIR haplotypes-HLA-ligands in endometriosis and control groups. The molecular interactions of KIR haplotypes-HLA-ligands were shown in the frequency of KIR haplotypes of HLA-ligands, which was calculated from the KIR haplotypes frequency of the total number of HLA ligands. The total number of HLA ligands is shown in Table 3. Two-sided Fisher's exact test was used to estimate the differences between endometriosis and control groups. n: number of cases with relevant genotypes, OR: odds ratio, CI: confidence interval.

in the proportion of NK cells facilitates endometrial cell invasion and persistent growth in endometriosis ${ }^{70}$. Maeda et al. demonstrated that the increase in KIR2DL1 levels in women with pelvic endometriosis can inhibit NK cell activity ${ }^{66}$. However, the activation of chronic NK cell activation can also play a role in endometriosis ${ }^{71}$. The upregulation of KIR2DS1 expression in peritoneal fluid has been detected in women with endometriosis ${ }^{72}$. Recently, bioinformatic analysis showed that KIR2DS2 expression is upregulated in the secretory phase of endometrium in women with endometriosis relative to control women ${ }^{73}$. Thus, the regulation of NK cell activity is a complex process and can affect the pathogenesis of endometriosis ${ }^{74}$. The final activation status of functional NK cells depends on the homeostasis of all NK cell activation/inhibitory receptors and the corresponding ligands. Then, NK cells are regulated in endometrium in women with endometriosis. Further studies will be worth elucidating the functional relevance of the presence of these receptors and ligand proteins in the endometrium. The limitation of this study is that only the stage III or stage IV endometriosis patients were enrolled to investigate the genetic associations. Thus, our results did not show any association between genes and severity of disease. Further clinically relevant studies on the severity of disease and genetic associations are required.

Our current findings demonstrated the association between KIR polymorphisms and HLA-C genotypes with endometriosis in women. It is the first study addressing KIR polymorphisms and HLA-C genotypes of women with stage III or IV endometriosis in Han Chinese women. The results suggested that HLA-C and KIR genotypes influence the susceptibility for endometriosis. Further studies should investigate the role of NK cells in the pathogenesis of endometriosis.

\section{Methods}

Patients and controls. Han Chinese women were categorized into the endometriosis $(\mathrm{n}=147)$ and control $(\mathrm{n}=117)$ groups. Endometriosis was diagnosed via laparoscopic examination and confirmed via histological assessment. A total of 147 women were classified under stage III or IV endometriosis in accordance with the Revised American Society for Reproductive Medicine Classification. Women in the control group underwent benign gynecological surgery and showed no evidence of endometriosis including myoma, teratoma, serous cystadenoma, ovarian cyst, ovarian stroma, dermoid cyst, mucinous cystadenoma, paratubal cyst, follicular cyst, simple cyst, hydrosalpinx, corpus luteum cyst, fibrous adhesion, and struma ovarii. Considering that autoimmune disorders are associated with $H L A-C$ alleles and $K I R$ genotypes, the exclusion criteria comprised autoimmune disorders. The protocol was approved by the Institutional Review Board of the Taipei Medical University Hospital, and all participants have informed consent. All experiments were performed in accordance with relevant guidelines and regulations.

DNA extraction and $H L A-C$ and $K I R$ genotype analysis. Genomic DNA was extracted using a DNA whole-blood kit following the manufacturer's instructions (Kurabo Industries, Osaka, Japan). HLA-C was genotyped using an HLAssure ${ }^{\mathrm{TM}}$ SE sequence-based typing kit (TBG Biotechnology Corp, Queensland, Australia), which was designed to determine $H L A-C$ alleles via polymerase chain reaction (PCR) amplification using a 
sequence-based typing method. Sequence data were processed using allele-typing software (AccuType ${ }^{\mathrm{TM}}$ ) to identify the $H L A-C$ alleles. The genotypes of the KIR genes were analyzed using the Lifecodes KIR-sequence-specific oligonucleotide (SSO) typing kit (Immucor Transplant Diagnostics, Inc., Stamford, USA) to identify the KIR loci amplified in the sample. The presence or absence of the $16 \mathrm{KIR}$ genes was determined using 20 different oligonucleotide probes targeting known KIR genes (KIR3DL3 as positive control, KIR2DL1, KIR2DL2*001-3/5, KIR2DL2*004, KIR2DL3, KIR2DL4, KIR2DL5, KIR2DP1, KIR3DL1, KIR3DL2, KIR2DS1, KIR2DS2, KIR2DS3, KIR2DS4*whole exon 4, KIR2DS4*whole exon 5, KIR2DS4*-deleted exon 5, KIR2DS5, KIR3DS1, $K I R 3 D S 1 * 049 \mathrm{~N}$, and KIR3DP1). The amplicons were analyzed on a Luminex instrument according to the manufacturer's instructions. The characteristics of full-length and truncated forms of KIR2DS4 were determined using the following three probes; probe 45: KIR2DS4*all full-length, probe 175: 2DS4*full-length Exon 5, and probe 234: 2DS4*deletion Exon 5. KIR genes are divided into centromeric and telomeric haplotypes ${ }^{75}$. In short, centromeric A/A haplotypes contained KIR2DL3 but not with KIR2DL2 and/or KIR2DS2, centromeric A/B haplotypes contained KIR2DL3 with KIR2DL2 and/or KIR2DS2, and centromeric B/B haplotypes contained KIR2DL2 and/ or KIR2DS2 but not KIR2DL3. Meanwhile, telomeric A/A haplotypes contained KIR3DL1 and KIR2DS4 but not KIR3DS1 or KIR2DS1, telomeric A/B haplotypes contained KIR3DL1 and KIR2DS4 with KIR3DS1 and/or KIR2DS1, and telomeric B/B haplotypes lacked KIR3DL1 and/or KIR2DS4 ${ }^{76}$.

Statistical analyses. HLA-C allele frequencies, the genotypes of the KIR genes and KIR-HLA-C pair frequency in endometriosis patients and control women were compared using the Fisher's exact test. Odds ratios (ORs) and 95\% confidence intervals (CIs) were calculated using the GraphPad Prism software (California, USA). $\mathrm{P}$ value $<0.05$ was considered statistically significant. Multiple tests were analyzed by the Bonferroni correction using the GraphPad Prism software. The normality was analyzed by the Kolmogorov-Smirnov test using IBM SPSS statistics version 22 (New York, USA). The continuous variables of patient demographic results were analyzed by the Mann-Whitney test using the GraphPad Prism software. The discontinuous variable of dysmenorrhea was analyzed by $\chi^{2}$ test using the GraphPad Prism software. The statistical power was analyzed by the $G^{*}$ Power version 3.1.9.4 $4^{77}$. The $\chi^{2}$ value was calculated by Hardy-Weinberg analysis $\left(\chi^{2}>3.841\right.$ showed the subgroup was deviating from the Hardy-Weinberg equilibrium).

Received: 26 September 2019; Accepted: 24 February 2020;

Published online: 17 March 2020

\section{References}

1. Rogers, P. A. et al. Priorities for endometriosis research: recommendations from an international consensus workshop. Reprod. Sci. 16, 335-346, https://doi.org/10.1177/1933719108330568 (2009).

2. Giudice, L. C. Clinical practice. Endometriosis. N. Engl. J. Med. 362, 2389-2398, https://doi.org/10.1056/NEJMcp1000274 (2010).

3. Giudice, L. C. \& Kao, L. C. Endometriosis. Lancet 364, 1789-1799, https://doi.org/10.1016/S0140-6736(04)17403-5 (2004).

4. Nnoaham, K. E. et al. Impact of endometriosis on quality of life and work productivity: a multicenter study across ten countries. Fertil. Steril. 96, 366-373 e368, https://doi.org/10.1016/j.fertnstert.2011.05.090 (2011).

5. Simpson, J. L., Elias, S., Malinak, L. R. \& Buttram, V. C. Jr. Heritable aspects of endometriosis. I. Genetic studies. Am. J. Obstet. Gynecol. 137, 327-331 (1980).

6. Moen, M. H. \& Magnus, P. The familial risk of endometriosis. Acta Obstet. Gynecol. Scand. 72, 560-564 (1993).

7. Kennedy, S., Mardon, H. \& Barlow, D. Familial endometriosis. J. Assist. Reprod. Genet. 12, 32-34 (1995).

8. Treloar, S. A., O'Connor, D. T., O'Connor, V. M. \& Martin, N. G. Genetic influences on endometriosis in an Australian twin sample. sueT@qimr.edu.au. Fertil. Steril.71,701-710 (1999).

9. Bischoff, F. Z. \& Simpson, J. L. Heritability and molecular genetic studies of endometriosis. Hum. Reprod. Update 6, 37-44 (2000).

10. Senturk, L. M. \& Arici, A. Immunology of endometriosis. J. Reprod. Immunol. 43, 67-83 (1999).

11. Gleicher, N., el-Roeiy, A., Confino, E. \& Friberg, J. Is endometriosis an autoimmune disease? Obstet. Gynecol. 70, 115-122 (1987).

12. Gleicher, N. Autoimmunity and reproductive failure. Ann. N. Y. Acad. Sci. 626, 537-544 (1991).

13. Ho, H. N. et al. Peritoneal natural killer cytotoxicity and CD25+ CD3+ lymphocyte subpopulation are decreased in women with stage III-IV endometriosis. Hum. Reprod. 10, 2671-2675 (1995).

14. Vigano, P. et al. Deficient antie ndometrium lymphocyte-mediated cytotoxicity in patients with endometriosis. Fertil. Steril. 56, 894-899 (1991)

15. Oosterlynck, D. J., Cornillie, F. J., Waer, M., Vandeputte, M. \& Koninckx, P. R. Women with endometriosis show a defect in natural killer activity resulting in a decreased cytotoxicity to autologous endometrium. Fertil. Steril. 56, 45-51 (1991).

16. Oosterlynck, D. J., Meuleman, C., Waer, M., Vandeputte, M. \& Koninckx, P. R. The natural killer activity of peritoneal fluid lymphocytes is decreased in women with endometriosis. Fertil. Steril. 58, 290-295 (1992).

17. Nothnick, W. B. Treating endometriosis as an autoimmune disease. Fertil. Steril. 76, 223-231 (2001).

18. Witz, C. A. Pathogenesis of endometriosis. Gynecol. Obstet. Invest. 53(Suppl 1), 52-62 (2002).

19. Shiina, T., Hosomichi, K., Inoko, H. \& Kulski, J. K. The HLA genomic loci map: expression, interaction, diversity and disease. J. Hum. Genet. 54, 15-39, https://doi.org/10.1038/jhg.2008.5 (2009).

20. Matzaraki, V., Kumar, V., Wijmenga, C. \& Zhernakova, A. The MHC locus and genetic susceptibility to autoimmune and infectious diseases. Genome Biol. 18, 76, https://doi.org/10.1186/s13059-017-1207-1 (2017).

21. Zhou, F. et al. Deep sequencing of the MHC region in the Chinese population contributes to studies of complex disease. Nat. Genet. 48, 740-746, https://doi.org/10.1038/ng.3576 (2016).

22. Blais, M. E., Dong, T. \& Rowland-Jones, S. HLA-C as a mediator of natural killer and T-cell activation: spectator or key player? Immunology 133, 1-7, https://doi.org/10.1111/j.1365-2567.2011.03422.x (2011).

23. Collins, K. L., Chen, B. K., Kalams, S. A., Walker, B. D. \& Baltimore, D. HIV-1 Nef protein protects infected primary cells against killing by cytotoxic T lymphocytes. Nat. 391, 397-401, https://doi.org/10.1038/34929 (1998).

24. Fellay, J. et al. A whole-genome association study of major determinants for host control of HIV-1. Sci. 317, 944-947, https://doi. org/10.1126/science.1143767 (2007)

25. Ho, P. Y. et al. Investigating the role of the HLA-Cw*06 and HLA-DRB1 genes in susceptibility to psoriatic arthritis: comparison with psoriasis and undifferentiated inflammatory arthritis. Ann. Rheum. Dis. 67, 677-682, https://doi.org/10.1136/ard.2007.071399 (2008).

26. Simmonds, M. J. et al. A novel and major association of HLA-C in Graves' disease that eclipses the classical HLA-DRB1 effect. Hum. Mol. Genet. 16, 2149-2153, https://doi.org/10.1093/hmg/ddm165 (2007). 
27. Vivier, E. et al. Innate or adaptive immunity? The example of natural killer cells. Sci. 331, 44-49, https://doi.org/10.1126/ science.1198687 (2011).

28. Paul, S. \& Lal, G. The Molecular Mechanism of Natural Killer Cells Function and Its Importance in Cancer Immunotherapy. Front. Immunol. 8, 1124, https://doi.org/10.3389/fimmu.2017.01124 (2017).

29. Middleton, D. \& Gonzelez, F. The extensive polymorphism of KIR genes. Immunology 129, 8-19, https://doi.org/10.1111/j.13652567.2009.03208.x (2010).

30. Falco, M., Moretta, L., Moretta, A. \& Bottino, C. KIR and KIR ligand polymorphism: a new area for clinical applications? Tissue Antigens 82, 363-373, https://doi.org/10.1111/tan.12262 (2013).

31. Kulkarni, S., Martin, M. P. \& Carrington, M. The Yin and Yang of HLA and KIR in human disease. Semin. Immunol. 20, 343-352, https://doi.org/10.1016/j.smim.2008.06.003 (2008).

32. Rajalingam, R. Human diversity of killer cell immunoglobulin-like receptors and disease. Korean J. Hematol. 46, 216-228, https:// doi.org/10.5045/kjh.2011.46.4.216 (2011).

33. Ruggeri, L. et al. Donor natural killer cell allorecognition of missing self in haploidentical hematopoietic transplantation for acute myeloid leukemia: challenging its predictive value. Blood 110, 433-440, https://doi.org/10.1182/blood-2006-07-038687 (2007).

34. Graef, T. et al. KIR2DS4 is a product of gene conversion with KIR3DL2 that introduced specificity for HLA-A*11 while diminishing avidity for HLA-C. J. Exp. Med. 206, 2557-2572, https://doi.org/10.1084/jem.20091010 (2009).

35. Cella, M., Longo, A., Ferrara, G. B., Strominger, J. L. \& Colonna, M. NK3-specific natural killer cells are selectively inhibited by Bw4positive HLA alleles with isoleucine 80. J. Exp. Med. 180, 1235-1242, https://doi.org/10.1084/jem.180.4.1235 (1994).

36. Cariani, E. et al. HLA and killer immunoglobulin-like receptor genes as outcome predictors of hepatitis C virus-related hepatocellular carcinoma. Clin. Cancer Res. 19, 5465-5473, https://doi.org/10.1158/1078-0432.CCR-13-0986 (2013).

37. Yen, J. H. et al. Major histocompatibility complex class I-recognizing receptors are disease risk genes in rheumatoid arthritis. J. Exp. Med. 193, 1159-1167 (2001).

38. Martin, M. P. et al. Cutting edge: susceptibility to psoriatic arthritis: influence of activating killer Ig-like receptor genes in the absence of specific HLA-C alleles. J. Immunol. 169, 2818-2822 (2002).

39. van der Slik, A. R. et al. KIR in type 1 diabetes: disparate distribution of activating and inhibitory natural killer cell receptors in patients versus HLA-matched control subjects. Diabetes 52, 2639-2642 (2003).

40. Shastry, A. et al. Combination of KIR 2DL2 and HLA-C1 (Asn 80) confers susceptibility to type 1 diabetes in Latvians. Int. J. Immunogenet. 35, 439-446, https://doi.org/10.1111/j.1744-313X.2008.00804.x (2008).

41. Middleton, D., Diler, A. S., Meenagh, A., Sleator, C. \& Gourraud, P. A. Killer immunoglobulin-like receptors (KIR2DL2 and/or KIR2DS2) in presence of their ligand (HLA-C1 group) protect against chronic myeloid leukaemia. Tissue Antigens 73, 553-560, https://doi.org/10.1111/j.1399-0039.2009.01235.x (2009).

42. Boyton, R. J. et al. HLA-C and killer cell immunoglobulin-like receptor genes in idiopathic bronchiectasis. Am. J. Respir. Crit. Care Med. 173, 327-333, https://doi.org/10.1164/rccm.200501-124OC (2006).

43. Montgomery, G. W. et al. The search for genes contributing to endometriosis risk. Hum. Reprod. Update 14, 447-457, https://doi. org/10.1093/humupd/dmn016 (2008).

44. Tariverdian, N. et al. Neuroendocrine-immune disequilibrium and endometriosis: an interdisciplinary approach. Semin. Immunopathol. 29, 193-210, https://doi.org/10.1007/s00281-007-0077-0 (2007).

45. Matarese, G., De Placido, G., Nikas, Y. \& Alviggi, C. Pathogenesis of endometriosis: natural immunity dysfunction or autoimmune disease? Trends Mol. Med. 9, 223-228 (2003).

46. Moen, M., Bratlie, A. \& Moen, T. Distribution of HLA-antigens among patients with endometriosis. Acta Obstet. Gynecol. Scand. Suppl. 123, 25-27 (1984).

47. Simpson, J. L., Malinak, L. R., Elias, S., Carson, S. A. \& Radvany, R. A. HLA associations in endometriosis. Am. J. Obstet. Gynecol. 148, 395-397 (1984).

48. Maxwell, C., Kilpatrick, D. C., Haining, R. \& Smith, S. K. No HLA-DR specificity is associated with endometriosis. Tissue Antigens 34, 145-147 (1989).

49. Ishii, K. et al. Studies on the human leukocyte antigen class I antigens in Japanese patients with macroscopically diagnosed endometriosis. Gynecol Obstet Invest 54, 150-153, 67882 (2002).

50. Ishii, K., Takakuwa, K., Mitsui, T. \& Tanaka, K. Studies on the human leukocyte antigen-DR in patients with endometriosis: genotyping of HLA-DRB1 alleles. Hum. Reprod. 17, 560-563 (2002).

51. Ishii, K., Takakuwa, K., Kashima, K., Tamura, M. \& Tanaka, K. Associations between patients with endometriosis and HLA class II; the analysis of HLA-DQB1 and HLA-DPB1 genotypes. Hum. Reprod. 18, 985-989 (2003).

52. Kitawaki, J. et al. Association of HLA class I and class II alleles with susceptibility to endometriosis. Hum. Immunol. 63, 1033-1038 (2002).

53. Roszkowski, P. I. et al. Susceptibility to ovarian endometriosis in Polish population is not associated with HLA-DRB1 alleles. Hum. Reprod. 20, 970-973, https://doi.org/10.1093/humrep/deh715 (2005).

54. Wang, X., Lin, Q. \& Guo, S. Study on polymorphism of human leukocyte antigen I in patients with endometriosis. Zhonghua Fu Chan Ke Za Zhi 36, 150-152 (2001).

55. Wang, X. et al. Study on polymorphism of human leukocyte antigen-DRB1 allele in patients with endometriosis. Zhonghua Fu Chan Ke Za Zhi 37, 346-348 (2002).

56. Zong, L., He, Y. \& Pan, D. Association of human leukocyte antigen-DQA1 with endometriosis of women in southern China. Zhonghua Fu Chan Ke Za Zhi 36, 405-407 (2001).

57. Kitawaki, J. et al. Association of killer cell immunoglobulin-like receptor genotypes with susceptibility to endometriosis. Am. J. Reprod. Immunol. 58, 481-486, https://doi.org/10.1111/j.1600-0897.2007.00533.x (2007).

58. Nowak, I. et al. Does the KIR2DS5 gene protect from some human diseases? PLoS One 5, e12381, https://doi.org/10.1371/journal. pone.0012381 (2010).

59. Nowak, I. et al. KIR2DS5 in the presence of HLA-C C2 protects against endometriosis. Immunogenetics 67, 203-209, https://doi. org/10.1007/s00251-015-0828-3 (2015).

60. Single, R. M., Martin, M. P., Meyer, D., Gao, X. \& Carrington, M. Methods for assessing gene content diversity of KIR with examples from a global set of populations. Immunogenetics 60, 711-725, https://doi.org/10.1007/s00251-008-0331-1 (2008).

61. Moesta, A. K. \& Parham, P. Diverse functionality among human NK cell receptors for the C1 epitope of HLA-C: KIR2DS2, KIR2DL2, and KIR2DL3. Front. Immunol. 3, 336, https://doi.org/10.3389/fimmu.2012.00336 (2012).

62. Gourraud, P. A., Meenagh, A., Cambon-Thomsen, A. \& Middleton, D. Linkage disequilibrium organization of the human KIR superlocus: implications for KIR data analyses. Immunogenetics 62, 729-740, https://doi.org/10.1007/s00251-010-0478-4 (2010).

63. NurWaliyuddin, H. Z. et al. Ancient Genetic Signatures of Orang Asli Revealed by Killer Immunoglobulin-Like Receptor Gene Polymorphisms. PLoS One 10, e0141536, https://doi.org/10.1371/journal.pone.0141536 (2015).

64. Tanaka, E., Sendo, F., Kawagoe, S. \& Hiroi, M. Decreased natural killer cell activity in women with endometriosis. Gynecol. Obstet. Invest. 34, 27-30 (1992).

65. Jeung, I., Cheon, K. \& Kim, M. R. Decreased Cytotoxicity of Peripheral and Peritoneal Natural Killer Cell in Endometriosis. Biomed. Res. Int. 2016, 2916070, https://doi.org/10.1155/2016/2916070 (2016). 
66. Matsuoka, S. et al. Expression of inhibitory-motif killer immunoglobulin-like receptor, KIR2DL1, is increased in natural killer cells from women with pelvic endometriosis. Am. J. Reprod. Immunol. 53, 249-254, https://doi.org/10.1111/j.1600-0897.2005.00271.x (2005).

67. Oosterlynck, D. J., Meuleman, C., Lacquet, F. A., Waer, M. \& Koninckx, P. R. Flow cytometry analysis of lymphocyte subpopulations in peritoneal fluid of women with endometriosis. Am. J. Reprod. Immunol. 31, 25-31 (1994).

68. Berkkanoglu, M. \& Arici, A. Immunology and endometriosis. Am. J. Reprod. Immunol. 50, 48-59 (2003).

69. Zhang, C. et al. Killer immunoglobulin-like receptor and human leukocyte antigen expression as immunodiagnostic parameters for pelvic endometriosis. Am. J. Reprod. Immunol. 55, 106-114, https://doi.org/10.1111/j.1600-0897.2005.00332.x (2006).

70. Herington, J. L., Bruner-Tran, K. L., Lucas, J. A. \& Osteen, K. G. Immune interactions in endometriosis. Expert. Rev. Clin. Immunol. 7, 611-626, https://doi.org/10.1586/eci.11.53 (2011).

71. Dias, J. A. Jr. et al. Patients with endometriosis of the rectosigmoid have a higher percentage of natural killer cells in peripheral blood. J. Minim. Invasive Gynecol. 19, 317-324, https://doi.org/10.1016/j.jmig.2011.12.021 (2012).

72. Wu, M. Y. et al. Increase in the expression of killer cell inhibitory receptors on peritoneal natural killer cells in women with endometriosis. Fertil. Steril. 74, 1187-1191 (2000).

73. Drury, J. A. et al. The dynamic changes in the number of uterine natural killer cells are specific to the eutopic but not to the ectopic endometrium in women and in a baboon model of endometriosis. Reprod. Biol. Endocrinol. 16, 67, https://doi.org/10.1186/s12958018-0385-3 (2018).

74. Thiruchelvam, U., Wingfield, M. \& O'Farrelly, C. Natural Killer Cells: Key Players in Endometriosis. Am. J. Reprod. Immunol. 74, 291-301, https://doi.org/10.1111/aji.12408 (2015).

75. Cooley, S. et al. Donors with group B KIR haplotypes improve relapse-free survival after unrelated hematopoietic cell transplantation for acute myelogenous leukemia. Blood 113, 726-732, https://doi.org/10.1182/blood-2008-07-171926 (2009).

76. Umemura, T. et al. KIR3DL1-HLA-Bw4 combination and IL28B polymorphism predict response to Peg-IFN and ribavirin with and without telaprevir in chronic hepatitis C. Hum. Immunol. 75, 822-826, https://doi.org/10.1016/j.humimm.2014.06.003 (2014).

77. Faul, F., Erdfelder, E., Buchner, A. \& Lang, A. G. Statistical power analyses using G*Power 3.1: tests for correlation and regression analyses. Behav. Res. Methods 41, 1149-1160, https://doi.org/10.3758/BRM.41.4.1149 (2009).

\section{Acknowledgements}

This work was supported by the Ministry of Science and Technology (grant number 104-2314-B-038063-MY2, grant number 106-2314-B-038-072, grant number 107-2314-B-038-006, grant number 108-2314B-038-003), Academia Sinica (grant number BM10501010036, grant number BM10601010024, grant number BM10701010027), National Health Research Institute (grant number MG-105-SP-07, grant number MG106-SP-07, grant number MG-107-SP-07) (CRT), and Ministry of Science and Technology (grant number 1072314-B-009-006) (YCC). This work was financially supported by the Center for Intelligent Drug Systems and Smart Bio-devices (IDS ${ }^{2}$ B) from The Featured Areas Research Center Program within the framework of the Higher Education Sprout Project by the Ministry of Education (MOE) in Taiwan.

\section{Author contributions}

Y.-C.C. designed the study, performed experiments, analysed the data and wrote the manuscripts, C.-H.C., M.-J.C., C.-W.C., P.-H.C, M.-H.Y., Y.-J.C., E.-M.T., P.-S.Y. and S.-Y.L. enrolled patients, and C.-R.T. guided the experimental design, enrolled patients and wrote the manuscripts.

\section{Competing interests}

The authors declare no competing interests.

\section{Additional information}

Correspondence and requests for materials should be addressed to C.-R.T.

Reprints and permissions information is available at www.nature.com/reprints.

Publisher's note Springer Nature remains neutral with regard to jurisdictional claims in published maps and institutional affiliations.

(c) (i) Open Access This article is licensed under a Creative Commons Attribution 4.0 International

License, which permits use, sharing, adaptation, distribution and reproduction in any medium or format, as long as you give appropriate credit to the original author(s) and the source, provide a link to the Creative Commons license, and indicate if changes were made. The images or other third party material in this article are included in the article's Creative Commons license, unless indicated otherwise in a credit line to the material. If material is not included in the article's Creative Commons license and your intended use is not permitted by statutory regulation or exceeds the permitted use, you will need to obtain permission directly from the copyright holder. To view a copy of this license, visit http://creativecommons.org/licenses/by/4.0/.

(C) The Author(s) 2020 